\title{
Efetividade dos métodos de descontaminação em máscaras de tecido com luz ultravioleta e gás ozônio
}

\author{
Effectiveness of decontamination methods in tissue masks with ultraviolet light and ozone gas \\ Eficacia de los métodos de descontaminación en mascarillas tisulares con luz ultravioleta y gas
}

ozono

Recebido: 04/11/2021 | Revisado: 10/11/2021 | Aceito: 11/11/2021 | Publicado: 18/11/2021

\author{
Débora Batista Pereira Alves \\ ORCID: https://orcid.org/0000.0002.4074.5440 \\ Instituto Educacional Santa Catarina - Faculdade Guaraí, Brasil \\ E-mail: deboralves10@ hotmail.com \\ Lídia Lira Saraiva \\ ORCID: https://orcid.org/0000-0002-1783-0612 \\ Instituto Educacional Santa Catarina - Faculdade Guaraí, Brasil \\ E-mail: lidialira1@outlook.com \\ Helen Patrícia de Oliveira Duarte Souza \\ ORCID: https://orcid.org/0000-0001-9264-3027 \\ Instituto Educacional Santa Catarina - Faculdade Guaraí, Brasil \\ E-mail: patricia.duarte@iescfag.edu.br \\ Mara Soares de Almeida Mota \\ ORCID: https://orcid.org/0000-0002-2068-3481 \\ Instituto Educacional Santa Catarina - Faculdade Guaraí, Brasil \\ E-mail: mara.almeida06@gmail.com \\ Drielly Lima Santana \\ ORCID: https://orcid.org/0000-0002-7971-350X \\ Instituto Educacional Santa Catarina - Faculdade Guaraí, Brasil \\ E-mail: drielly.santana@iescfag.edu.br
}

\begin{abstract}
Resumo
Com a pandemia de COVID-19, houve significativo aumento no consumo de Equipamentos de Proteção Individual, ocasionando escassez de máscaras para os profissionais da área da saúde, sendo que as máscaras em tecido desempenharam um papel fundamental na contenção da transmissão de doenças virais e bacterianas na população em geral. Diante da demanda do uso de máscaras, houve uma necessidade de pesquisar novos agentes antissépticos que pudessem proporcionar a sua reutilização. Portanto, este estudo tem como objetivo analisar a eficácia dos processos de descontaminação por ozônio e luz UV-C nas máscaras de proteção de uso não profissional em diferentes tipos de tecidos, diante da contaminação experimental por $S$. aureus. As máscaras foram recortadas em pequenos pedaços e contaminadas com uma solução $10^{8} \mathrm{UFC} / \mathrm{ML}$ e comparada com a escala de Mac Farland a 0,5, descontaminadas com gás ozônio e UV-C. Os resultados mostraram eficiência em ambos os processos, ressaltando um melhor desempenho do gás ozônio mostrou em relação à UV-C. A distância da amostra em relação ao aparelho de descontaminação, o tempo de exposição e o modelo de equipamento de UV-C e ozônio podem influenciar na obtenção de resultados mais eficientes em relação a descontaminação. Mesmo com a grande variedade de produtos químicos disponíveis, busca-se reduzir os microrganismos das máscaras com UV-C ou ozônio, como forma alternativa, sem alterar estruturalmente os tecidos, e comprometer sua eficiência. O estudo pode contribuir para o lançamento de mais equipamentos que utilizem esse tipo de descontaminação, deixando esse processo mais simples e barato para a população.
\end{abstract}

Palavras-chave: Efetividade; Métodos de descontaminação; Máscaras; Luz UV-C; Ozônio.

\begin{abstract}
With the COVID-19 pandemic, there was a significant increase in the consumption of Personal Protective Equipment, causing a shortage of masks for health professionals, and tissue masks played a fundamental role in containing the transmission of viral and bacterial diseases in the general population. Given the demand for the use of masks, there was a need to research new antiseptic agents that could provide their reuse. Therefore, this study aims to analyze the efficacy of ozone and UV-C light decontamination processes in protective masks for non-professional use in different types of tissues, in view of experimental contamination by S. aureus. The masks were cut into small pieces and contaminated with a $10^{8} \mathrm{CFU} / \mathrm{ML}$ solution and compared with the Mac Farland scale at 0.5, decontaminated with ozone gas and UV-C. The results showed efficiency in both processes, emphasizing a better performance of ozone gas showed in relation to UV-C. The distance from the sample in relation to the decontamination apparatus, the exposure
\end{abstract}


time and the UV-C and ozone equipment model may influence the achievement of more efficient results in relation to decontamination. Even with the wide variety of chemicals available, it is sought to reduce microorganisms of masks with UV-C or ozone, as an alternative form, without structurally altering the tissues, and compromising their efficiency. The study can contribute to the launch of more equipment that uses this type of decontamination, making this process simpler and cheaper for the population.

Keywords: Effectiveness; Decontamination methods; Masks; UV-C light; Ozone.

\section{Resumen}

Con la pandemia de COVID-19, hubo un aumento significativo en el consumo de Equipos de Protección Personal, causando una escasez de máscaras para los profesionales de la salud, y las máscaras de tejido jugaron un papel fundamental en la contención de la transmisión de enfermedades virales y bacterianas en la población general. Dada la demanda del uso de mascarillas, era necesario investigar nuevos agentes antisépticos que pudieran proporcionar su reutilización. Por lo tanto, este estudio tiene como objetivo analizar la eficacia de los procesos de descontaminación de ozono y luz UV-C en máscaras protectoras para uso no profesional en diferentes tipos de tejidos, en vista de la contaminación experimental por $S$. aureus. Las máscaras se cortaron en trozos pequeños y se contaminaron con una solución de $10^{8}$ UFC / ML y se compararon con la escala Mac Farland a 0.5, descontaminadas con gas ozono y UV-C. Los resultados mostraron eficiencia en ambos procesos, destacando un mejor desempeño del gas ozono mostrado en relación con los rayos UV-C. La distancia de la muestra en relación con el aparato de descontaminación, el tiempo de exposición y el modelo de equipo UV-C y ozono pueden influir en el logro de resultados más eficientes en relación con la descontaminación. Incluso con la amplia variedad de productos químicos disponibles, se busca reducir los microorganismos de las mascarillas con UV-C u ozono, como forma alternativa, sin alterar estructuralmente los tejidos, y comprometiendo su eficiencia. El estudio puede contribuir al lanzamiento de más equipos que utilicen este tipo de descontaminación, haciendo que este proceso sea más sencillo y barato para la población.

Palabras clave: Eficacia; Métodos de descontaminación; Máscaras; Luz UV-C; Ozono.

\section{Introdução}

Os seres humanos estão constantemente expostos a partículas suspensas no ar provenientes de fontes biológicas como vírus, bactérias e fungos, o que pode ocasionar muitas doenças infecciosas (Vanetti et al., 2020). Em decorrência da incidência de diversas doenças infecciosas já conhecidas e potenciais, se faz necessário a prevenção quanto aos cuidados individuais e coletivos, especialmente o uso de máscaras para proteção facial (Cadilho et al., 2020).

De acordo com a Agência Nacional de Vigilância Sanitária (2020), existem diversos modelos de máscaras faciais, como as máscaras de proteção de uso não profissional, máscaras cirúrgicas e equipamentos de proteção respiratória, conhecidos também como respiradores. Diferentes profissionais, como os da área da saúde, estética, mineração, indústria de produtos químicos, soldagem e higienização de ambientes insalubres, fazem uso desse tipo de equipamento para proteção das vias respiratórias. As máscaras do tipo N95 e PFF2 são destinadas para uso de profissionais da saúde, e as confeccionadas artesanalmente, em tecidos, como algodão e tricoline, são destinadas para a população em geral na presença de prováveis contaminações. AS máscaras cirúrgicas são confeccionadas em Tecido Não Tecido (TNT) de uso médico-hospitalar e devem ser utilizadas por pacientes com sintomas de infecção respiratória, por profissionais de saúde e de apoio.

Sob as circunstâncias atuais da pandemia COVID-19, houve escassez de equipamentos de proteção individual, principalmente de máscaras para os profissionais da área de saúde, sendo que as máscaras de tecido desempenharam um papel fundamental na contenção da transmissão de doenças virais e bacterianas para população em geral, mesmo que, na literatura mais recente, a eficácia do uso delas ainda é inconclusivo (Peloso et al., 2020).

Segundo Pereira-Ávila et al., (2020), as máscaras de proteção de uso não profissional (tecido), não são consideradas Equipamentos de Proteção Individual (EPIs) adequados para proteção, em consequência de sua baixa capacidade de filtragem e purificação do ar, pois podem acumular umidade, e para que isso não ocorra é necessário que o modelo escolhido contenha no mínimo três camadas de tecido. Caso sejam confeccionadas em algodão, devem conter quatro camadas, adaptando-se ao rosto, cobrindo totalmente o nariz e a boca e não apresentarem folgas laterais. As máscaras de tecido possuem menor eficiência de filtração quando comparadas às máscaras cirúrgicas e respiradores. Contudo, se bem projetadas e usadas corretamente podem fornecer proteção contra microrganismos (Chughtai et al., 2020). 
A bactéria Staphylococcus aureus é considera um dos principais agentes etiológicos responsáveis por infecções nosocomiais e comunitárias, cada vez mais constantes, geralmente constitui a flora residente da mucosa nasal, sendo considerado um importante patógeno humano, responsável por mais de 30\% das infecções hospitalares (Almeida, 2014).

Diante da alta demanda por uso de máscaras, se faz necessário pesquisar novos agentes antissépticos que possam proporcionar a reutilização delas. $\mathrm{O}$ ozônio $\left(\mathrm{O}_{3}\right)$ tem se tornado um elemento químico bastante utilizado no controle de descontaminação em diferentes áreas. Em razão do seu elevado poder oxidante tornou-se eficiente na esterilização de materiais biológicos, eliminando microrganismos mediante a oxidação dos constituintes da estrutura celular microbiana como a parede celular e membrana plasmática, provocando a destruição e posteriormente morte celular (Caetano, 2018). Outro método de descontaminação que vem se destacando quanto a eficácia e segurança na inativação de microrganismos é a radiação ultravioleta C (UV-C). A radiação ultravioleta é a fração do espectro eletromagnético que compreende os comprimentos de onda que permanecem abaixo da luz visível para seres humanos (Silva, et al., 2020).

Tendo em vista o atual cenário da pandemia de COVID-19, intensificou-se o uso de máscaras de proteção por toda a população, com destaque especial para aquelas confeccionadas artesanalmente, seguindo ou não as recomendações da ANVISA. O exponencial crescimento deste tipo de proteção fez surgir a seguinte problemática: $O$ processo de descontaminação amplamente utilizado pela população em geral é realmente eficiente? Existem métodos mais eficientes neste processo de descontaminação?

Considerando que produtos químicos associados ou não a processos mecânicos assepsia tendem a destruir as fibras de tecido, o presente estudo tem como objetivo analisar a eficácia dos processos de descontaminação por ozônio e luz UV-C nas máscaras de proteção de uso não profissional de diferentes tipos de tecidos, diante da contaminação experimental por Staphylococcus aureus.

\section{Metodologia}

O presente estudo caracteriza-se por uma pesquisa descritivo-exploratório com abordagem qualitativa segundo (Lakatos, 2021), realizada entre os meses de março a outubro de 2021 no laboratório de Análises Clínicas da Clínica de Educação para Saúde do Instituto Educacional Santa Catarina, no município de Guaraí, Tocantins.

A pesquisa analisou a efetividade de métodos de descontaminação de máscaras em tecido com luz ultravioleta e gás ozônio diante da contaminação experimental por Staphylococcus aureus.

Os modelos de máscaras utilizadas na pesquisa foram selecionados de acordo com as recomendações da Agência Nacional de Vigilância Sanitária (ANVISA), Ministério da Saúde e Organização Mundial da Saúde (OMS).

Foram excluídas do estudo as máscaras cirúrgicas e respiradores N95 ou PFF2, amplamente utilizadas por profissionais da saúde, pois a pesquisa direcionou-se apenas para máscaras de tecido utilizadas por grande parte da população.

As máscaras de tecidos selecionadas, foram divididas em três grupos:

- Grupo 1: Máscaras de tricoline com três camadas;

- Grupo 2: Máscaras de tricoline com duas camadas;

- Grupo 3: Máscaras de $100 \%$ algodão com duas camadas.

Para a realização da pesquisa as máscaras passaram pelos processos de contaminação com a bactéria $S$. aureus, descontaminação com UV-C e Ozônio e testes de eficiência dos tecidos.

\section{Preparação da amostra bacteriana}

A preparação bacteriana para o estudo, foi por meio da utilização da coleta de material realizada com swab estéril, friccionando a parede das fossas nasais dos próprios pesquisadores. Após a coleta, o material foi inoculado diretamente em 
placas de Petri contendo Ágar de infusão de cérebro e coração (Brain and Heart Infusion - BHI) e incubadas a $37^{\circ} \mathrm{C}$ por 48 horas em estufa bacteriológica. As colônias que se desenvolveram foram selecionadas POR suas características macroscópicas (colônias redondas, lisas, elevadas, brilhantes, com coloração esbranquiçadas ou amarelo-dourado intenso), sendo em seguida, realizado a coloração de Gram e prova da catalase para identificação de bactérias do gênero Staphylococcus.

As colônias classificadas macroscopicamente foram utilizadas para confecção de lâminas para análise microscópica. A técnica da coloração de Gram foi realizada, cobrindo-se o esfregaço com cristal violeta desprezando-o após 1 minuto. Em seguida, o esfregaço foi coberto com lugol por 1 minuto, em sequência, foi lavado em água corrente. O esfregaço foi descorado com álcool-cetona por 5 segundos e, novamente, lavado em água corrente. Após esse processo, foi utilizado fucsina de Gram por 30 segundos, lavado em água corrente e deixando secar em temperatura ambiente (Xavier, 2017).

A prova catalase foi realizada transferindo colônias com características de Staphylococcus para uma lâmina com o auxílio de alça bacteriológica, seguida por uma gota de peróxido de hidrogênio $\left(\mathrm{H}_{2} \mathrm{O}_{2}\right)$ a 3\% observando a formação de bolhas. A prova é considerada positiva após produção rápida e sustentada de bolhas de gás ou efervescência (Von \& Mamizuka, 2013)

Para a identificação do Staphylococcus aureus foram realizados os testes da coagulase na lâmina e em tubo. Grande parte das Cepas de Staphylococcus aureus tem a coagulase ligada a superfície da parede celular, reagindo com o fibrinogênio plasmático ocasionando assim a coagulação (Von \& Mamizuka, 2013).

No teste da coagulase em lâmina, transferiu-se a colônia com características de Staphylococcus cultivada em Ágar BHI para uma lâmina contendo 2 gotas de solução salina, emulsionou-se a colônia isolada, acrescentou-se uma gota de plasma citratado, homogeneizou e observou a aglutinação após 10 segundos.

Para o teste da coagulase em tubo foi adicionado $0,1 \mathrm{ml}$ de caldo BHI em um tubo de ensaio juntamente com a colônia selecionada que apresentava características de S. aureus e incubado por 24 horas em estufa bacteriológica à $37^{\circ} \mathrm{C}$, posteriormente foi adicionado $0,5 \mathrm{ml}$ de plasma citratado e incubado novamente a $37^{\circ} \mathrm{C}$ por 4 horas, após foi verificado a formação do coágulo. $\mathrm{O}$ teste baseia-se na presença da coagulase livre que reage com um fator plasmático formando um complexo que atua sobre o fibrinogênio formando a fibrina, sendo considerado positivo com a formação do coágulo, observando-se através da inclinação do tubo de ensaio a $90^{\circ}$ na vertical (Von \& Mamizuka, 2013).

\section{Processo de contaminação das amostras}

Antes de qualquer procedimento, foram coletadas amostras das máscaras, para observação da isenção de microrganismos. Eles foram realizados por meio de swab, inserido em PBS estéril friccionado na superfície de cada máscara, seguido pela inoculação das amostras no meio de cultura Ágar BHI e incubação por 48 horas.

Após a preparação bacteriana a amostra foi submetida ao processo de preparação de uma Solução a $10^{8} \mathrm{UFC} / \mathrm{ml}$

\section{Preparação da Solução a $10^{8}$ UFC/ml}

Com o auxílio da alça bacteriológica, foi realizada a coleta das bactérias semeadas no Ágar BHI, introduzida em tubo com 3ml de solução fisiológica estéril e comparada com a escala de Mac Farland à 0,5.

\section{Procedimento para contaminação}

As máscaras foram cortadas em pequenos pedaços de $1 \mathrm{~cm} \times 1 \mathrm{~cm}$, dispostos em um barbante colocado na capela de fluxo laminar, presos com pequenos prendedores, nos quais foi aspergido a solução com $10^{8} \mathrm{UFC} / \mathrm{ML}$ de $S$. aureus por 3 vezes distante $15 \mathrm{~cm}$ do tecido cortado, aguardando o processo de secagem por aproximadamente $30 \mathrm{~min}$, conforme mostra a Figura 1. 
Juntamente com o processo de contaminação das máscaras testadas, realizou-se a contaminação de um controle para os tipos de tecidos, e os tecidos contaminados foram submetidos a avaliação do processo de recuperação microbiana para comprovação da existência de microrganismos na solução aspergida, seguida pela inoculação das amostras em placas com o meio de cultura Ágar BHI e incubação por 48 horas.

Figura 1: Processo de contaminação com a solução $10^{8} \mathrm{UFC} / \mathrm{ML}$ de S. aureus.

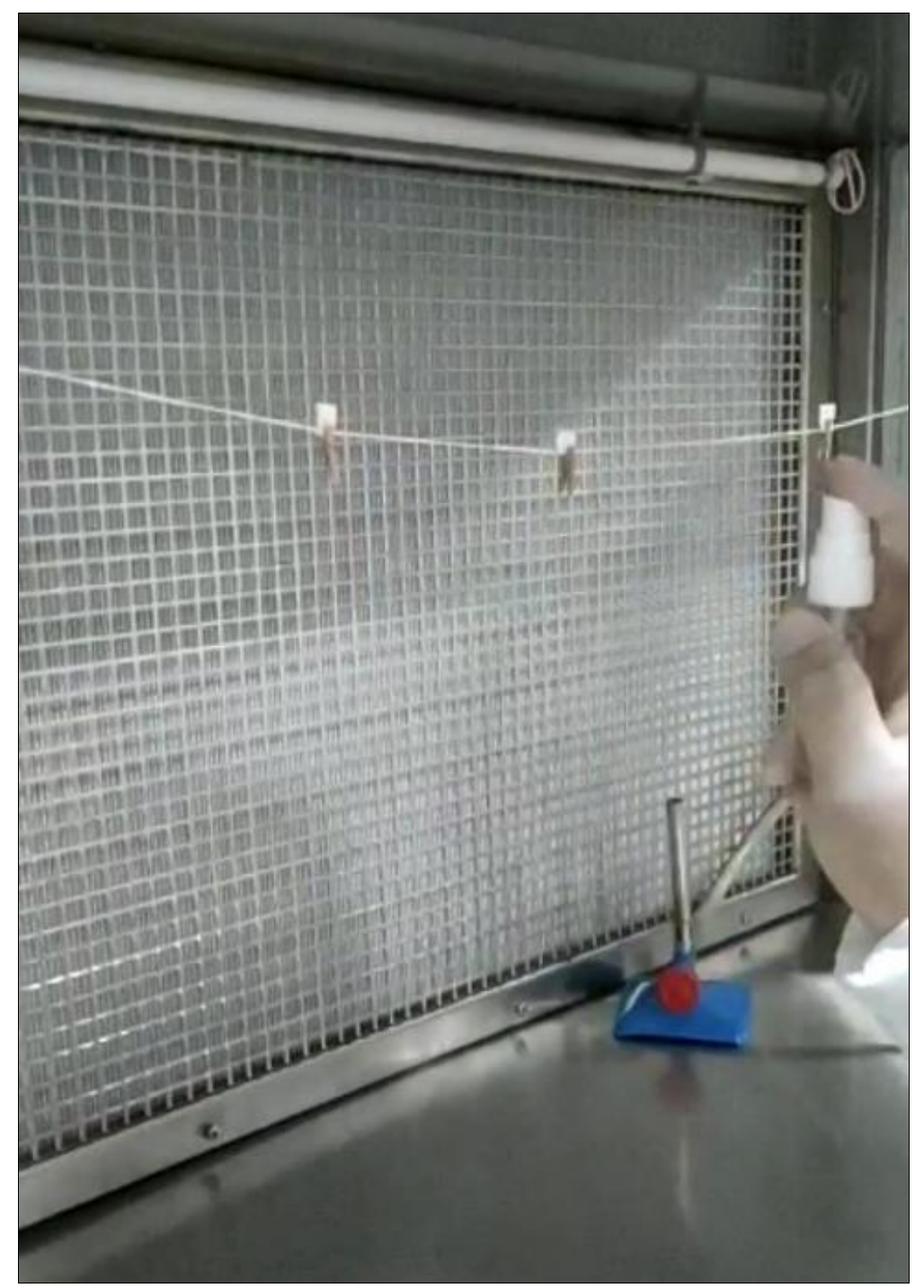

Fonte: Autores.

\section{Processo de descontaminação por ozonizador}

Após o processo de preparação da amostra, com a identificação da bactéria Staphylococcus aureus e o processo de contaminação com os pequenos pedaços das máscaras, eles passaram pelo processo de descontaminação com o equipamento ozonizador.

O equipamento utilizado foi o gerador de ozônio da marca Vosoco de 220v, com 1000mg de ozônio por minuto, portátil, silencioso com baixo consumo de energia. O princípio de funcionamento do equipamento é de alta tensão, utilizando o ar seco ou oxigênio do ar como matéria prima para produzir o $\mathrm{O}_{3}$.

No processo de descontaminação com o ozônio, foi confeccionado uma câmara de vidro no formato retangular nas dimensões 40 × 60 × $30 \mathrm{~cm}$ para melhorar a aplicação do mesmo, com a parte superior composta por uma tampa removível 
para inserção e retirada do material. Para iniciar o processo, foi colocado dentro da câmara de vidro um Erlenmeyer de $125 \mathrm{ml}$ contendo os pedaços das máscaras contaminadas e a mangueira do ozonizador fixada no mesmo. A exposição das máscaras ao ozônio foi primeiramente no tempo 15 minutos, seguido pelo tempo de 30 e 45 minutos. Após esse processo realizado, as máscaras foram submetidas ao processo de recuperação microbiana, realizados em triplicata. Esse método de descontaminação foi semelhante a metodologia descrita por Zanzarini (2019).

\section{Avaliação do processo de descontaminação por ozônio com recuperação microbiana}

Após a descontaminação com ozônio, foram colocados pedaços recortados das máscaras em $1 \mathrm{ml}$ de solução fisiológica em um tubo de ensaio, submetidas a agitação mecânica (Vórtex) por 30s para recuperação microbiana, e posteriormente realizado a centrifugação. Após o processo de centrifugação foi coletado $10 \mu \mathrm{m}$ do sedimento e semeado no Ágar BHI, incubado a $37^{\circ} \mathrm{C}$ por 48 horas onde verificou-se o a ocorrência ou não de crescimento bacteriano com contagem das UFC.

\section{Processo de descontaminação por UV-C em capela e fluxo laminar}

Para descontaminação com UV-C foi utilizado uma capela de fluxo laminar horizontal de baixa turbulência, modelo HV - Q216F20HV com lâmpada fluorescente de 20 Watts e lâmpada germicida (luz UV-C) de 20 Watts. Os pequenos pedaços de máscaras previamente contaminados foram dispostos em um barbante colocado aproximadamente $10 \mathrm{~cm}$ da luz ultravioleta na capela de fluxo laminar, presos com pequenos prendedores, sendo este procedimento realizado em triplicata.

Inicialmente os pedaços de máscaras foram expostos a luz UV-C no tempo de 15 minutos, seguido pelo teste de $30 \mathrm{e}$ 45 minutos. Posteriormente foi realizado o processo de recuperação microbiana a fim de testar a eficácia do respectivo método e para realização destes procedimentos foram utilizados os equipamentos de proteção individual (EPIs).

\section{Avaliação do processo de descontaminação por UV-C com recuperação microbiana}

Após a descontaminação com o UV-C, foram colocados pedaços recortados das máscaras em $1 \mathrm{ml}$ de solução fisiológica dentro de um tubo de ensaio, submetidas a agitação mecânica no aparelho Vórtex por 30s para recuperação microbiana, e posteriormente realizado a centrifugação. Após o processo de centrifugação foi coletado $10 \mu \mathrm{L}$ do sedimento e semeado no Ágar BHI, incubado a $37^{\circ} \mathrm{C}$ por 48 horas onde verificou-se o a ocorrência ou não de crescimento bacteriano com contagem das UFC.

\section{Análise da integridade estrutural e funcional do tecido das máscaras após descontaminação por Ozônio e UV-C}

A integridade estrutural dos tecidos das máscaras foi avaliada após os processos de descontaminação por ozônio e UV-C, observando a ocorrência de alteração nas fibras de cada modelo de máscara testada. Esses processos foram realizados através da análise no microscópico óptico com fotografia e comparação do tecido antes e após os processos de descontaminação.

\section{Controle com a comparação da eficiência de filtração entre os tecidos utilizados nos processos de descontaminação}

Antes dos procedimentos foram coletadas amostras das máscaras, para observação da isenção de microrganismos. Eles foram realizados a através de swab inserido em PBS estéril friccionado na superfície de cada máscara, seguida pela inoculação das amostras em meio de cultura Ágar BHI e Ágar Sal Manitol, com incubação por 48 horas.

Os 3 modelos de máscaras testadas passaram pela avaliação da eficiência de filtração, realizado por meio da contaminação, utilizando o borrifador plástico com $3 \mathrm{ml}$ de suspensão a $10^{8} \mathrm{UFC} / \mathrm{ml}$ de $S$. aureus, em fase exponencial de 
crescimento por 3 vezes na posição anterior a máscara testada, seguida pela placa de Petri contendo o Ágar Sal Manitol, para avaliar o crescimento das bactérias que transpassaram as camadas das máscaras testadas. As placas foram incubadas em estufa microbiológica a $37^{\circ} \mathrm{C}$ por 48 horas, posteriormente foi realizada a contagem das UFC.

Figura 2. Fluxograma de distribuição das máscaras.

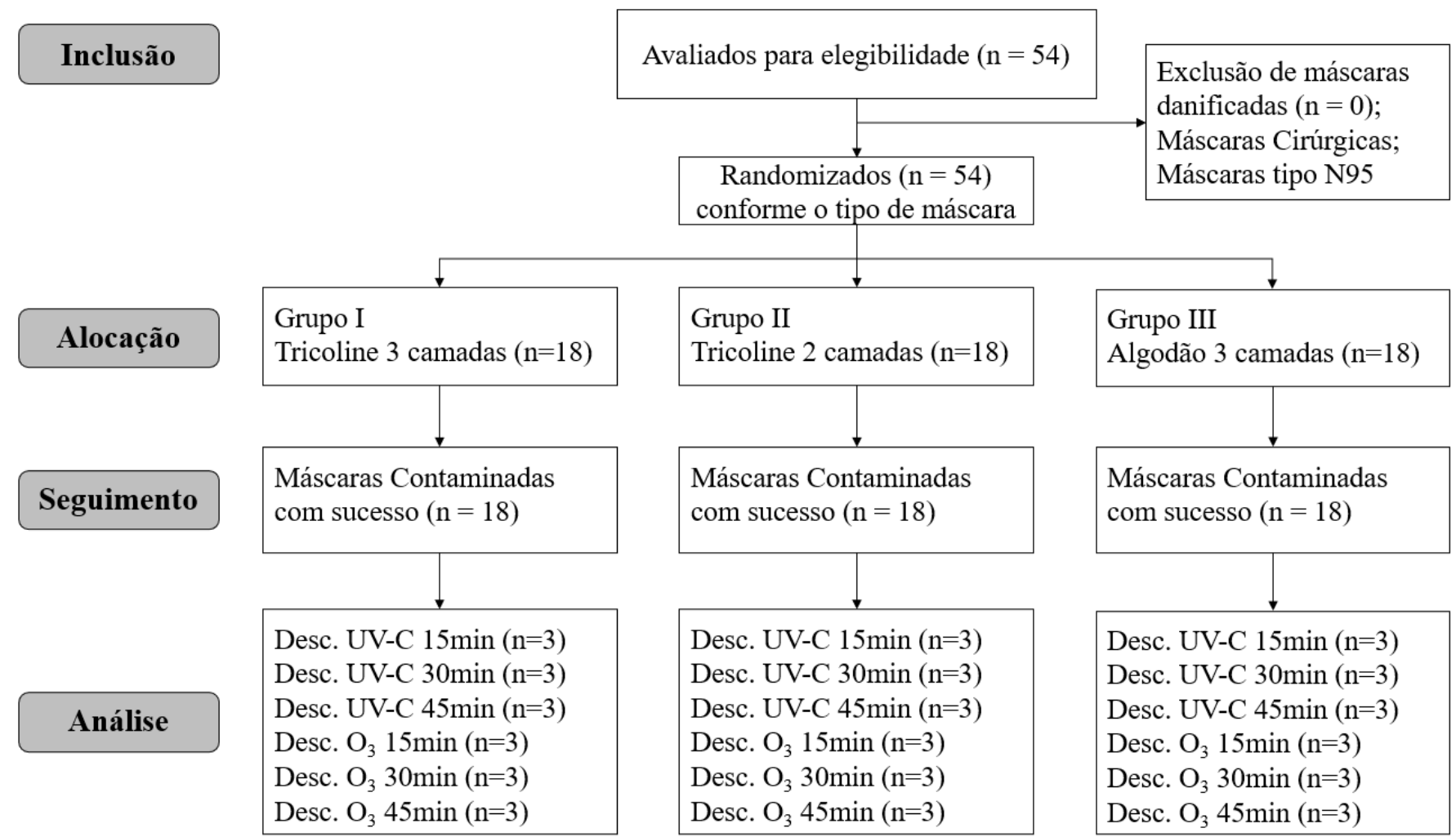

Fonte: Autores.

\section{Resultados e Discussão}

No processo de preparação da amostra bacteriana, identificamos o crescimento de colônias, com características macroscópicas de Staphylococcus. Estes tipos de colônias foram identificados pela sua formação redonda, lisa, elevada, brilhante, com coloração acinzentada ou amarelo-dourado nas placas semeadas no Ágar BHI. Para sua confirmação, foram realizadas análises microscópicas quanto a presença de bactérias Gram-positivas, de acordo com a metodologia descrita no estudo de Xavier (2017), onde as bactérias que apresentaram a coloração azul violeta são designadas de Gram-positivas, e as de coloração vermelha são designadas de Gram-negativas. A Figura 3 apresenta a imagem microscópica de bactérias Grampositivas da amostra cultivada na presente pesquisa. 
Figura 3. Imagem comprovando a presença de bactérias Gram-positivas do gênero Staphylococcus.

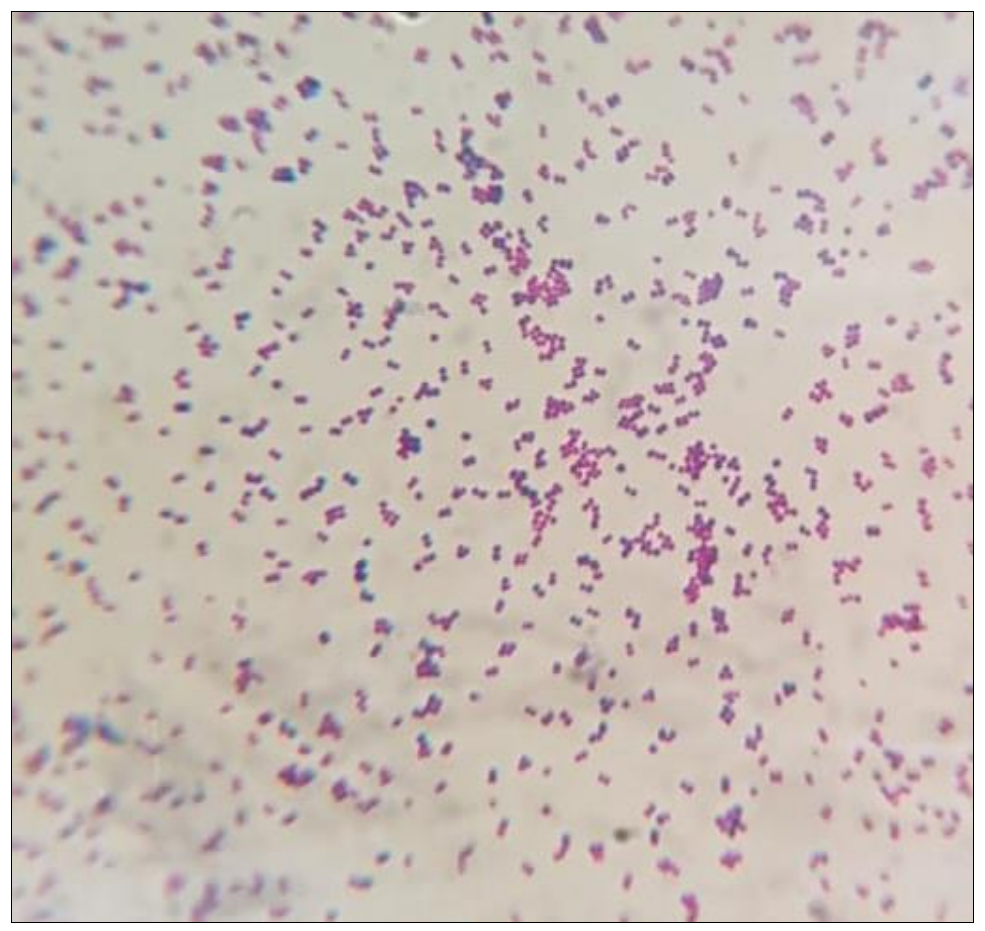

Fonte: Autores (2021).

A prova da catalase para diferenciação do gênero Staphylococcus apresentou o resultado positivo com produção rápida e sustentada com bolhas de gás ou efervescência através do contato das colônias com características de Staphylococcus e o peróxido de hidrogênio $\left(\mathrm{H}_{2} \mathrm{O}_{2}\right)$ de acordo com a metodologia proposta Von \& Mamizuka (2013) e alinhado aos estudos de Paula et al. (2019), que diferenciou o Staphylococcus do Streptococcus utilizando prova da catalase ao pesquisar os microrganismos encontrados nos fones de ouvido. Conforme mostra a Figura 4.

Figura 4. Resultado positivo do Teste de Catalase segundo Von \& Mamizuka (2013).

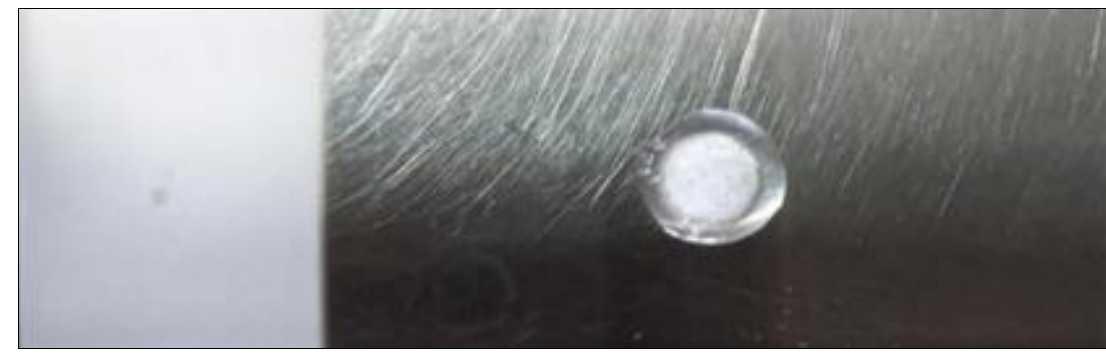

Fonte: Autores (2021).

Para a identificação da espécie $S$. aureus, realizou-se a prova da coagulase em lâmina colocando duas gotas de salina, emocionando uma colônia isolada a ser testada, depois colocar uma gota de plasma, mistura e observar se houve aglutinação em 10 segundos de acordo com a metodologia descrita por Von \& Mamizuka (2013), indo de encontro ao estudo de Paula et al. (2019), que realizou aprova da coagulase para diferenciar espécies de Staphylococcus, onde coagulase positivo denomina-se Staphylococcus aureus e coagulase negativo Staphylococcus spp.

Para a confirmação do resultado positivo do teste de coagulase em lâminas, foram realizados os testes em tubos de ensaio conforme metodologia descrita por Von \& Mamizuka (2013), apresentando o resultado positivo após 24 horas de incubação com a visualização da formação de coágulo observado através da inclinação do tubo. Os resultados vão de encontro 
ao estudo realizado por Espósito (2015), que utilizou o teste de coagulase livre em tudo para comparar a coagulase realizada com plasma de coelho e plasma humano utilizando 34 isolados de S. aureus.

\section{Descontaminação}

O gás ozônio mostrou-se muito eficaz no processo de descontaminação das máscaras, reduzindo a quantidade de colônias encontradas após o processo de descontaminação e ressuspensão microbiana. As máscaras utilizadas como controle também forma submetidas ao processo de contaminação, mas sem a realização da descontaminação, comprovando que no líquido aspergido nas máscaras continham $S$. aureus.

Como indicado na tabela 1 , as diferenças entre os métodos de descontaminação foram significativas. Constatou-se que após 15 minutos de aplicação do gás ozônio a contagem média de UFC era 0,3 tanto para máscaras de tricoline de duas quanto para as de três camadas, já as máscaras de algodão apresentaram média de 1,3 UFC para o mesmo tempo de descontaminação.

Tendo em vista a comprovação da existência de colônias após o tempo de 15 minutos, o processo de descontaminação por gás ozônio foi repetido, com tempo de 30 minutos. Para este tempo de exposição houve redução para zero colônias nas máscaras de tricoline de duas e três camadas, permanecendo ainda 1,3 UFC nas máscaras de algodão. Adicionados mais 15 minutos, elevando o tempo total de descontaminação para 45 minutos, observou-se e eliminação por completo de UFC nas amostras. Este achado corrobora com os resultados de Gonzaga (2018), que utilizou o gás ozônio para descontaminar diferentes microrganismos, entre eles o S. aureus nos resíduos gerados em um hospital, comprovando a eficácia do ozônio na aplicação técnica como bactericida e fungicida.

Segundo o estudo de Zanzarini (2019), o uso do gás ozônio para descontaminar canetas de bisturi elétrico, mostrou-se muito eficiente com a exposição das peças contaminadas ao gás nos tempos de 15 minutos independente da carga microbiana, observando a descontaminação de 10 minutos de exposição para bactérias e 15 minutos para leveduras.

Para o processo de descontaminação com luz UV-C, utilizando a capela de fluxo laminar, os resultados da tabela 1 apontam diferenças significativas na desinfecção do $S$. aureus conforme os tempos de exposição aumentam. Após a exposição por 15 minutos, as máscaras de tricoline de três camadas apresentaram média de 1,7 UFC, enquanto as máscaras de tricoline de duas camadas tinham esse número elevado para 4,7 UFC, e finalmente as de algodão com média de 4 UFC.

Seguindo a mesma metodologia utilizada com o gás ozônio, elevou-se o tempo de exposição a luz UV-C para 30 minutos, constatando uma melhora significativa na descontaminação das máscaras de tricoline com duas camadas, que passaram a 0,7 UFC, em contraponto a uma melhora mais discreta nas máscaras de tricoline com três camadas e algodão, passando respectivamente para média de 1,3 e 3 UFC.

Com uma terceira e última exposição, agora de 45 minutos, podemos observar a descontaminação por completo das máscaras de tricoline com três camadas e a redução nas máscaras de tricoline de duas camadas para 0,3 UFC e para 1 UFC nas máscaras de algodão.

Nos estudos de Corrêa et al. (2017), foi avaliado a eficiência de um novo equipamento portátil o Surface UV-C, baseado em uma lâmpada de vapor de mercúrio de baixa pressão, onde através da descontaminação in vitro aplicando o UV-C em diferentes superfícies hospitalares e em diferentes espécies de microrganismos entre eles o S. aureus, demonstrou que o equipamento foi muito eficiente na descontaminação das superfícies com uma distância de $1 \mathrm{~cm}$ da amostra a $254 \mathrm{~nm}$ e produz uma irradiância de $13 \mathrm{~mW} / \mathrm{cm}^{2}$, diminuindo os microrganismos em mais de 75\%. Com esse estudo é possível verificar que a distância da amostra em relação a lâmpada UV-C tem grande influência nos processos de descontaminação com UV-C. Os processos estão representados em algumas amostras nas Figuras 5, 6 e 7. 
Research, Society and Development, v. 10, n. 15, e138101522846, 2021

(CC BY 4.0) | ISSN 2525-3409 | DOI: http://dx.doi.org/10.33448/rsd-v10i15.22846

Tabela 1. Unidades Formadoras de Colônia (UFC) identificadas após os dois processos de descontaminação

\begin{tabular}{l|c|c|c|c|c|c}
\cline { 2 - 8 } Tipos de Máscara & \multicolumn{3}{|c|}{ UV-C } & \multicolumn{3}{c}{ Ozônio } \\
\hline Algodão 2 camadas & $\begin{array}{c}45 \\
\text { minutos* }\end{array}$ & $\begin{array}{c}30 \\
\text { minutos* }\end{array}$ & $\begin{array}{c}15 \\
\text { minutos* }\end{array}$ & $\begin{array}{c}45 \\
\text { minutos* }\end{array}$ & $\begin{array}{c}30 \\
\text { minutos* }\end{array}$ & $\begin{array}{c}15 \\
\text { minutos* }\end{array}$ \\
\hline Tricoline 2 camadas & 1,0 & 3,0 & 4,0 & 0,0 & 1,3 & 1,3 \\
\hline Tricoline 3 camadas & 0,3 & 0,7 & 4,7 & 0,0 & 0,0 & 0,3 \\
\hline
\end{tabular}

* Média de UFC das máscaras analisadas

Fonte: Autores (2021).

Figura 5. Após descontaminação com 15 minutos de exposição a UV-C e Ozônio.

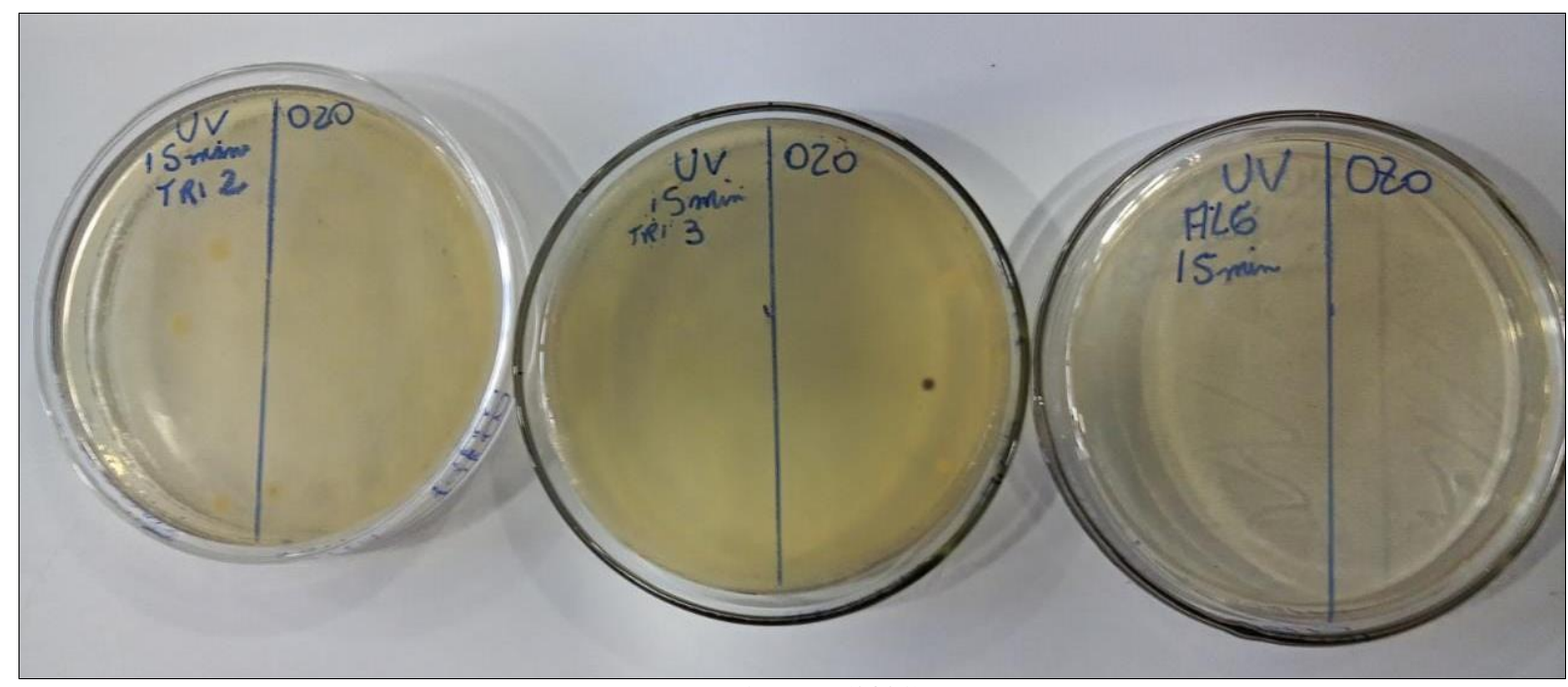

Fonte: Autores (2021).

Figura 6. Após descontaminação com 30 minutos de exposição a UV-C e Ozônio.

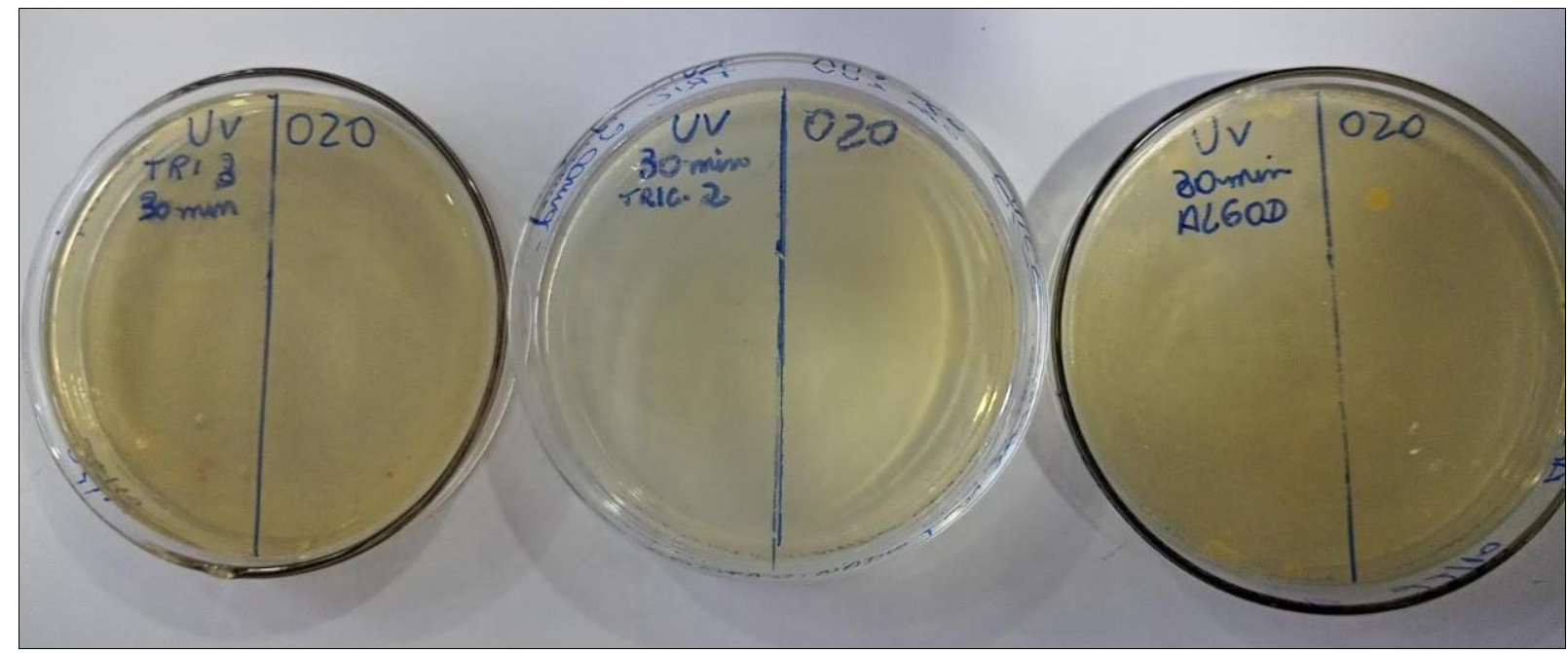

Fonte: Autores (2021). 
Figura 7. Após descontaminação com 45 minutos de exposição a UV-C e Ozônio.

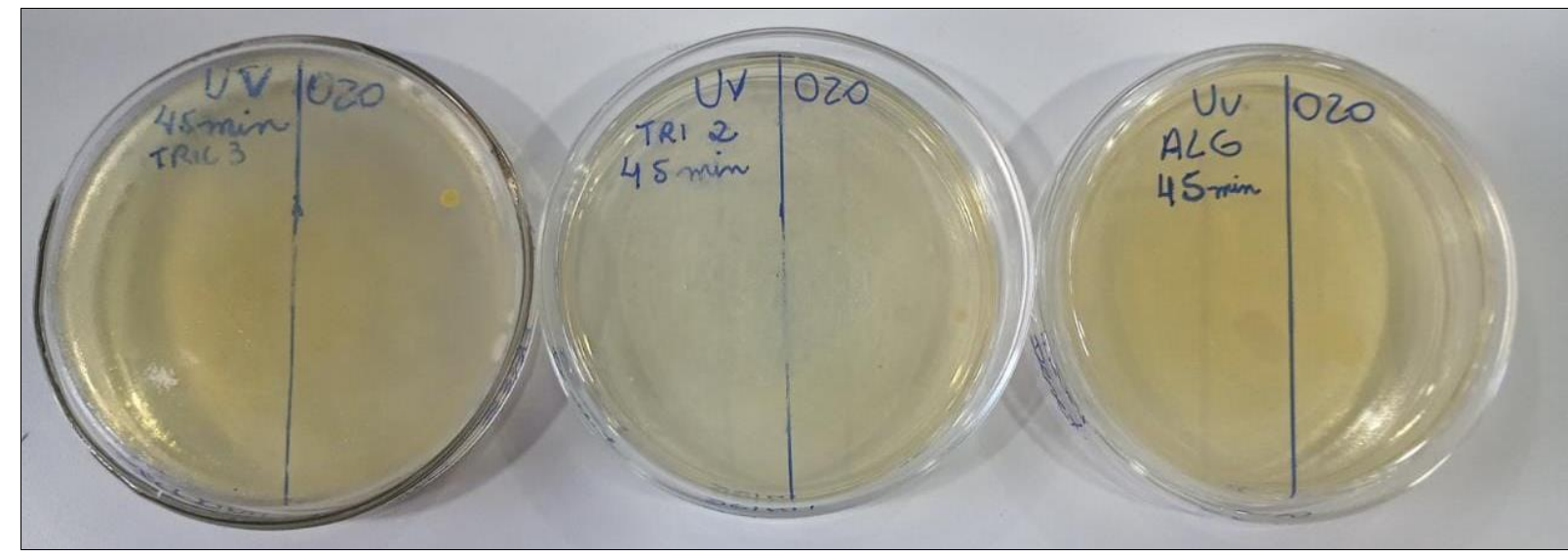

Fonte: Autores (2021).

\section{Controle -Teste de eficiência dos tecidos antes do processo de descontaminação}

O estudo avaliou a capacidade de filtração dos tecidos utilizados antes do processo de descontaminação como controle para a verificação da presença de contaminação por $S$. aureus diante da permeabilidade de cada tipo de tecido utilizado no estudo. Anteriormente a aspersão do S. aureus, as amostras foram submetidas a coleta com swab estéril, semeado em Ágar BHI e Ágar Sal Manitol, após 48 horas de incubação em estufa bacteriológica a $37^{\circ} \mathrm{C}$, e não apresentaram crescimento, constatando que as máscaras utilizadas nos processos de descontaminação estavam isentas de microrganismos e apresentaram no controle apenas os microrganismos aspergidos contento a solução a $10^{8} \mathrm{UFC} / \mathrm{ml}$ de $S$. aureus comparada com a escala de Mac Farland à 0,5 e aspergida a uma distância de $15 \mathrm{~cm}$.

Através da tabela 2 com a análise dos controles, podemos ressaltar a diferença da eficiência dos tecidos diante dos microrganismos, evidenciando que as máscaras de tricoline 3 camadas permitiram a passagem de 83 UFC apresentando mais eficiente na proteção em relação as máscaras de algodão duas camadas, com a contagem de 283 UFC e tricoline 2 camadas com 157 UFC (representada na Figura 7). Segundo a OMS as máscaras fabricadas de tecido devem possuir pelo menos três camadas, e se porventura forem confeccionadas exclusivamente de algodão, tenham pelo menos quatro camadas (Chaves et al., 2020). Na literatura os autores publicaram artigos semelhantes sobre a eficiência das máscaras de tecido. Bhattacharjee et al., (2020), relataram a existência de evidências inconclusivas a respeito do desempenho de filtragem de tecidos disponíveis para confecção de máscaras. Silva et al., (2020), expuseram que o conhecimento referente a utilização e eficiência das máscaras confeccionadas de tecido são limitados, em relação a proteção contra agentes de transmissão respiratória.

Nos estudos de Konda (2020), verificou-se a eficiência de filtração de diferentes tecidos utilizados na confecção das máscaras, ressaltando a importância de estudos futuros no design das máscaras de tecido para melhorar fatores como umidade decorrente da expiração, repetidos ciclos de lavagem evidenciando que o uso das máscaras de tecido pode fornecer proteção significativa contra microrganismos.

Para Araruna et al., (2021), as máscaras de tecido quando comparadas a outros grupos, como as máscaras cirúrgicas e N95 são menos eficazes para proteção contra infecções respiratórias, devido à pequena filtração desses materiais, ao processo de reutilização (que pode aumentar risco de contaminação) e à retenção de umidade na superfície das máscaras de tecido, ressaltando que pesquisas futuras seriam necessárias para avaliação da eficiência dessas máscaras de tecido quando usadas globalmente pela população. Os resultados estão apresentados na Tabela 2 e Figura 8. 
Tabela 2. Contagem de UFC nos controles indicando os microrganismos que ultrapassaram as camadas das máscaras testadas na pesquisa.

\begin{tabular}{l|c}
\hline \multicolumn{1}{c|}{ Tipo de Máscara } & Número de UFC \\
\hline Máscara de Algodão 2 camadas & 283 \\
\hline Máscara de Tricoline 2 camadas & 157 \\
\hline Máscara de Tricoline 3 camadas & 83 \\
\hline
\end{tabular}

Fonte: Autores.

Figura 8. Controles com crescimento de S.aureus em Ágar Sal Manitol que ultrapassaram as camadas de 3 modelos de máscaras de tecido com (distância de aspersão $15 \mathrm{~cm}$ ).

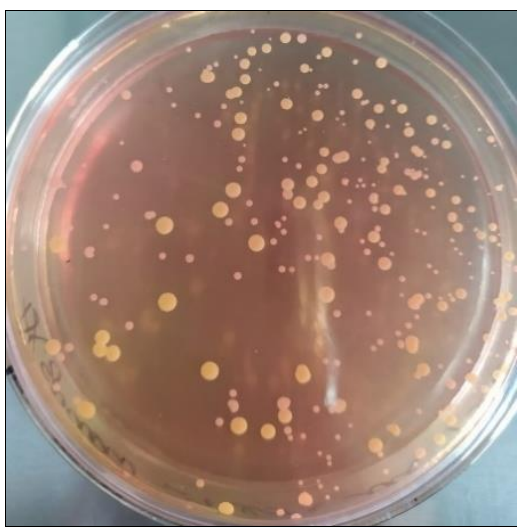

Máscara de Algodão 2 camadas

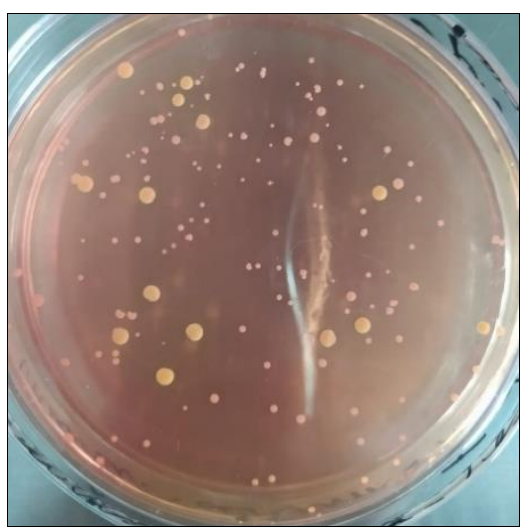

Máscara de Tricoline 2 camadas

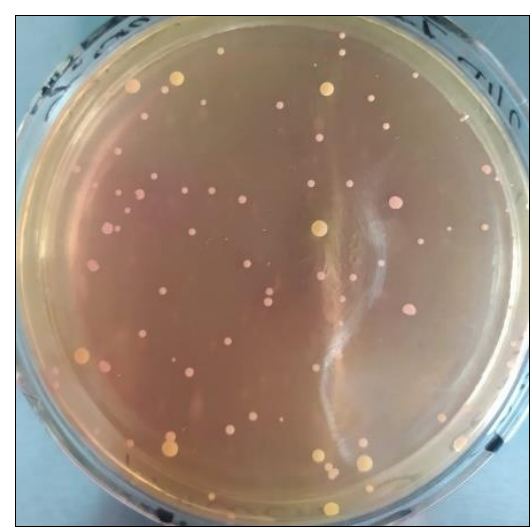

Máscara de Tricoline 3 camadas

Fonte: Autores (2021).

\section{Análise das fibras dos tecidos}

Após os processos de descontaminação com ozônio e luz ultravioleta, analisou-se as fibras dos três grupos de máscaras utilizadas no experimento (máscara de tricoline três camadas; máscara de tricoline 2 camadas e máscara de algodão 2 camadas). Cada máscara foi analisada microscopicamente e fotografada antes e depois da descontaminação, onde não foi observado nenhuma alteração na integridade e funcionalidade de suas fibras de acordo com as imagens apresentadas nas Figuras 9 e 10.

Seresirikachorn (2021), em seu estudo avaliou a eficácia de diferentes métodos de descontaminação buscando viabilizar a reutilização dos respiradores N95 e máscaras de tecido não tecido, evidenciando que entre os métodos utilizados estavam a luz ultravioleta-C (UV-C) testada em diferentes equipamentos entre eles um gabinete de fluxo laminar com luz UVC , nos tempos de exposição variando entre 15, 20, 30 e 45 minutos ressaltando que a estrutura física e eficiência da filtração das máscaras não foram alteradas após os processos de descontaminação. 
Figura 9. Visualização microscópica das fibras dos tecidos analisados antes da descontaminação.

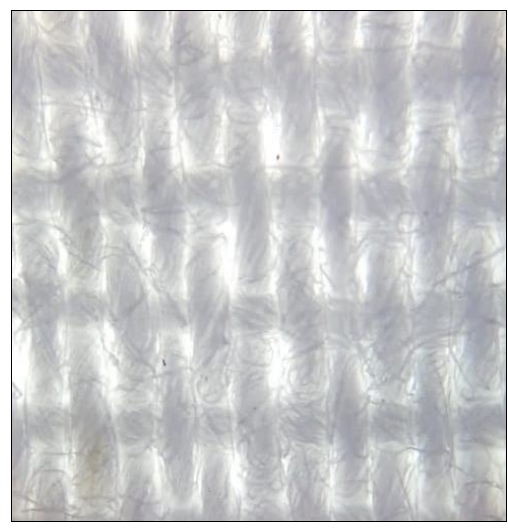

Fibras de tricoline 3 camadas

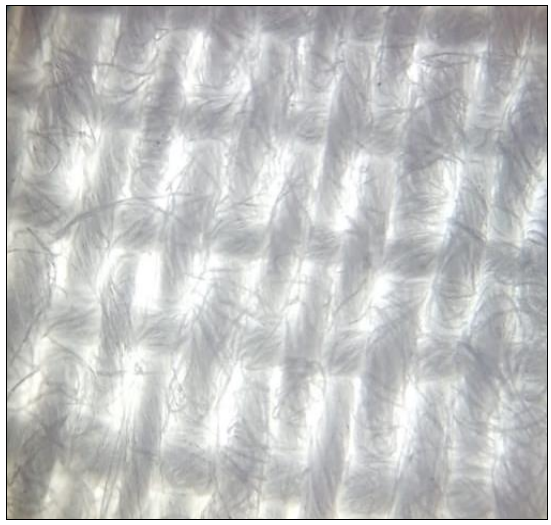

Fibras de tricoline 2 camadas

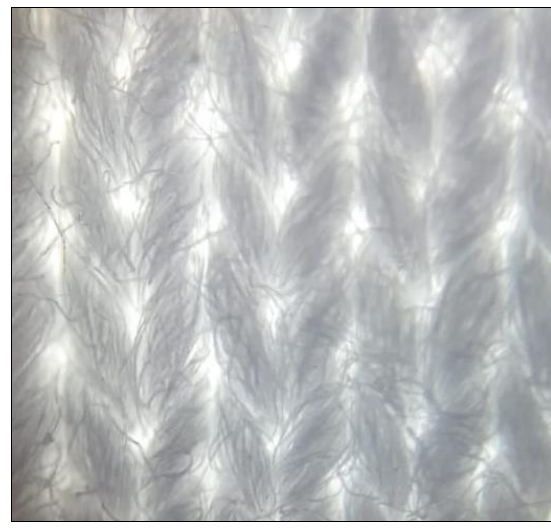

Fibras de algodão 2 camadas

Fonte: Autores (2021).

Figura 10. Visualização microscópica das fibras dos tecidos analisados após a descontaminação.

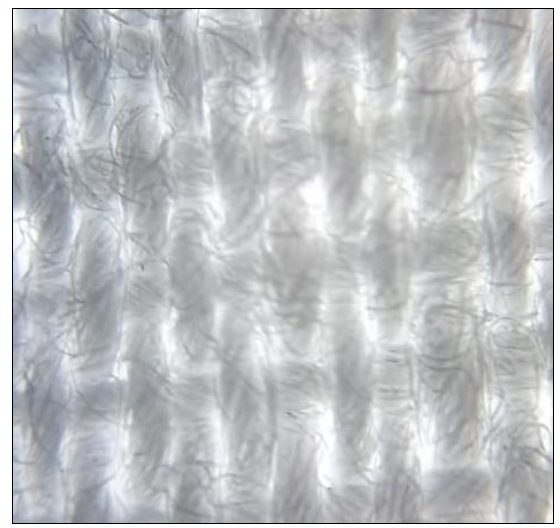

Fibras de tricoline 3 camadas

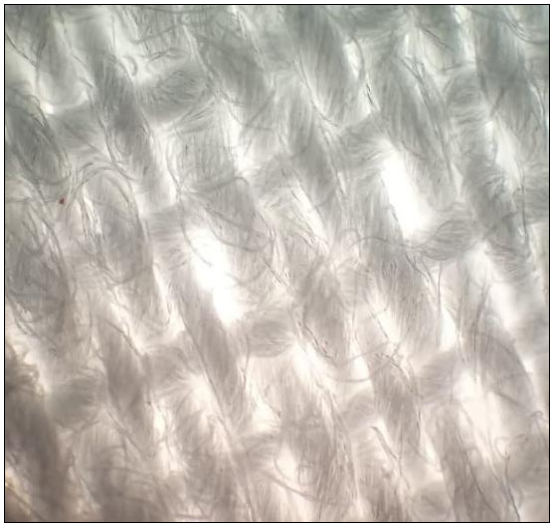

Fibras de tricoline 2 camadas

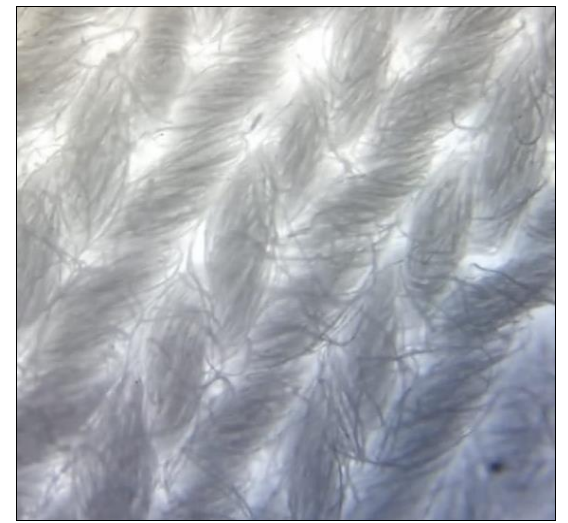

Fibras de algodão 2 camadas

Fonte: Autores (2021).

\section{Considerações Finais}

Este estudo avaliou a eficiência de dois processos de descontaminação: o gás ozônio $\left(\mathrm{O}_{3}\right)$ e a luz UV-C do equipamento de fluxo unidirecional (EFU) horizontal (capela de fluxo laminar). Ao final evidenciou-se que ambos os processos são eficientes, ressaltando que o gás ozônio apresentou melhor desempenho em relação ao UV-C.

Constatou-se neste estudo que a distância da amostra contaminada em relação aos aparelhos da descontaminação de luz ultravioleta e ozônio, o tempo de exposição destas amostras e o modelo dos equipamentos utilizados no processo, são variáveis que podem influenciar na obtenção de resultados mais eficientes.

Mesmo com a grande variedade de produtos químicos disponíveis para descontaminação de máscaras faciais, busca-se reduzir os microrganismos das máscaras com a utilização de luz UV-C ou ozônio, como forma alternativa, pois estes dois últimos não agridem estruturalmente os tecidos, não comprometendo desta forma a eficiência das máscaras. O estudo pode contribuir para o lançamento de mais equipamentos que utilizem esse tipo de descontaminação, tornando esse processo mais simples e acessível economicamente para a população. 


\section{Referências}

Almeida, G. C. M. D. (2014). Estafilococcias, colonização nasal por Staphylococcus spp. e os fatores associados em pacientes hospitalizados em Caicó-RN. Recuperado de: https://repositorio.ufrn.br/bitstream/123456789/22755/1/EstafilococciasColonizacaoNasal_Almeida_2014.pdf

Araruna, F. O. S., Moraes, M. B. C., Araruna, F. B., Luz, T. R. S. A., Serejo, A. P. M., do Amaral, F. M. M., \& Coutinho, D. F. (2021). Máscaras de tecido na prevenção da COVID-19: expectativa ou realidade? Revista de Saúde Coletiva da UEFS, 11(1), 5929. http://periodicos.uefs.br/index.php/saudecoletiva/article/download/5929/5910

Bhattacharjee, S., Bahl, P., Chughtai, A. A., \& MacIntyre, C. R. (2020). Last-resort strategies during mask shortages: optimal design features of cloth masks and decontamination of disposable masks during the COVID-19 pandemic. BMJ open respiratory research, 7(1), e000698. DOI:10.1136/bmjresp-2020000698

Brasil, Ministério da Saúde, \& Agência Nacional de Vigilância Sanitária. (2020). Orientações Gerais-Máscaras faciais de uso não profissional. http://portal.anvisa.gov.br/documents/219201/4340788/NT+M\%C3\%A1scaras.pdf/bf430 184-8550-42cb-a975-1d5e1c5a10f7

Cadilho, J. C. R., Pereira, C. M., \& Omena, T. A. (2020). Saúde coletiva através dos séculos; a construção de um conhecimento em saúde frente à diferentes doenças que assolaram a humanidade. Research, Society and Development, 9(12). https://www.rsdjournal.org/index.php/rsd/article/download/10671/9624

Caetano, M. H. (2018). Gás ozônio: avaliação da eficácia de desinfecção de ambientes. Dissertação de Mestrado, Universidade Estadual Paulista "Júlio de Mesquita Filho", Campus de São José do Rio Preto, São Paulo, https://repositorio.unesp.br/handle/11449/154405

Chaves, N. S. G., Ribeiro, J., Lopes, D. C., \& de Macedo, G. E. (2020). Novo normal? O Uso de Máscaras na Pandemia de Covid-19. Revista Saúde e Inovação, 1(1), 1-21. https://saudeinovacao.com/index.php/revista/article/download/19/5

Chughtai, A.A., Seale, H., \& Macintyre, C. (2020). Eficácia de máscaras de pano para proteção contra síndrome respiratória aguda grave Coronavírus 2. Doenças Infecciosas Emergentes, 26(10), 1-5. https://doi.org/10.3201/eid2610.200948.

Corrêa, T. Q., Blanco, K. C., Inada, N. M., Hortenci, M. D. F., Costa, A. A., Silva, E. D. S., ... \& Bagnato, V. S. (2017). Manual operated ultraviolet surface decontamination for healthcare environments. Photomedicine and laser surgery, 35(12), 666-671. DOI: https://doi.org/10.1089/pho.2017.4298

Espósito, M. C., Oliveira, D. A. F. D., Quinheito, D. S., \& Romão, J. V. (2015). Avaliação do desempenho do plasma humano em relação ao plasma de coelho no teste da coagulase livre. Rev. bras. anal. clin, 110-112. https://pesquisa.bvsalud.org/portal/resource/pt/lil-775390

Gonzaga, T. N., \& Kozusny-Andreani, D. I. (2018). Utilização de gás ozônio na desinfecção de resíduos de serviços de saúde. Revista Interdisciplinar de Estudos em Saúde, 125-139. doi: http://doi.org/10.33362/ries.v7i2.1428

Konda, A., Prakash, A., Moss, G. A., Schmoldt, M., Grant, G. D., \& Guha, S. (2020). Aerosol filtration efficiency of common fabrics used in respiratory cloth masks. ACS nano, 14(5), 6339-6347. https://pubs.acs.org/doi/abs/10.1021/acsnano.0c03252

Lakatos, E. M. (Coautor). (2021). Fundamentos de metodologia científica (9. ed. atual). São Paulo: Atlas.

Paula, J. C. K., Pietruchinski, E., \& Coquito, D. G. (2019). Pesquisa de microrganismos patogênicos em fones de ouvido. Revista Journal of Health-ISSN 2178-3594, 1. http://cescage.com.br/revistas/index.php/JournalofHealth/article/download/948/420

Peloso, R.M., Cotrin, P., Marques, T. de F., Pinzan-Vercelino, C. R.M.., Pelloso, S.M., \& Freitas, K.M. S. de. (2020). O uso generalizado de máscaras faciais durante as pandemias COVID-19: uma revisão da literatura. Pesquisa, Sociedade e Desenvolvimento, 9(10), e6089108576. https://doi.org/10.33448/rsdv9i10.8576

Pereira-Ávila, F. M. V., Lam, S. C., Góes, F. G. B., Gir, E., Pereira-Caldeira, N. M. V., Teles, S. A., ... \& Silva, A. C. D. O. (2020). Factors associated with the use and reuse of face masks among Brazilian individuals during the COVID-19 pandemic. Revista Latino-Americana de Enfermagem, 28. DOI: https://doi.org/10.1590/1518-8345.4604.3360

Seresirikachorn, K., Phoophiboon, V., Chobarporn, T., Tiankanon, K., Aeumjaturapat, S., Chusakul, S., \& Snidvongs, K. (2021). Decontamination and reuse of surgical masks and N95 filtering facepiece respirators during the COVID-19 pandemic: A systematic review. Infection Control \& Hospital Epidemiology, 42(1), 25-30. doi:10.1017/ice.2020.379

Silva, E. A., Barbosa, I. W. M., Palma, J. C. N., Brandão, M. V., Taveira, R. A., Meyer, R. F., \& Junior, O. H. A. (2020). Sistema de descontaminação de máscaras baseado no efeito luminescente causado por espectro ultravioleta (UV-C). https://2020.latinoware.org/wpcontent/uploads/2021/03/LatinScience_2020_paper_8.pdf

Vanetti, M. D., Oliveira, C. D. C., Almeida, B. C., \& Vanetti, M. C. D. (2020). Bioaerossóis em ambientes hospitalares. Boletim do Curso de Medicina da UFSC, 6(2), 24-30. DOI: https://doi.org/10.32963/bcmufsc.v6i2.4346

Von Nowakonski, Â., \& Mamizuka, E. M. (2013). Capítulo 1: Estafilococos, Estreptococos, Enterococos e outros. In Brasil, Agência Nacional de Vigilância Sanitária. Microbiologia Clínica para o Controle de Infecção Relacionada à Assistência à Saúde. Módulo 6: Detecção e identificação de bactérias de importância médica (pp.7-14). Brasília: Agência Nacional de Vigilância Sanitária

Xavier, H. C. M. de C. (2017). Manual de bacteriologia e de enteroparasitos [manual]. Natal, RN: EDUFRN. http://repositorio.ufrn.br

Zanzarini, T. J., \& Kozusny-Andreani, D. I. (2019). Efeito do gás ozônio na descontaminação de canetas de bisturi elétrico. Revista Ibero-Americana de Ciências Ambientais, 10(4), 112-120. https://www.sustenere.co/index.php/rica/article/download/CBPC2179-6858.2019.004.0009/1681 